\title{
Transparencia, orden público y habeas data 2015
}

(Constitucional Electoral)

José de Jesús Covarrubias Dueñas*

\section{Resumen}

Existen grandes problemas entre los derechos de las personas, transparencia y el habeas data, respecto de la Grundnorm, Norma Rectora o Constitución; dado que todas las personas deben ser respetadas y dentro de la libertad de expresión, se debe privilegiar a la dignidad humana.

En estas circunstancias, existe la libertad de expresión en el ciberespacio, pero se debe respetar el derecho de las personas a su intimidad o a la protección de datos personales, todas las personas somos iguales y libres.

Respecto a la materia constitucional y electoral, las autoridades, pueden tener acceso a la información de ciudadanos para su registro como candidatos, simplificando los trámites, pero respetando el habeas data de los ciudadanos y de toda persona, lo cual, por el momento es de urgente necesidad en beneficio de la República.

Palabras clave: Transparencia, Protección Datos Personales y Habeas Data.

\section{Transparency, public order and habeas data 2015}

\section{(Constitutional Electoral)}

\begin{abstract}
There are problems of norms between human rights and personal dignity, transparency and habeas data; because de Grundnorm, Rector Norm or Constitution says: all persons ought to respect, but, there are freedom of speech, then, what is first.

In this circumstance, there is freedom in the highway or cyberspace, but de human person have a right of habeas data; in this aspect, is evident the Grundnorm: the dignity of human persona is the first valor for protection = Grundrechte; all the people is same, have a liberties fundamentals.
\end{abstract}

*Universidad de Guadalajara, México.jjcovarrubias61@yahoo.com.mx 
In this way in right electoral constitutional, all authorities, have information for review requests for candidates, then, this authorities can access to information for this effects; but, only for rights of elections and rights constitutionals, this information ought to be respect in the context habeas data, is necessary proceedings and easy carpets, in this form the Republic is more efficiency.

Key words: Transparency, Protection Personal Information and Habeas Data.

\section{Sumario:}

1. Introducción 2. Conceptos básicos y problemática. 2.1. ¿Qué es un valor? 2.2. ¿Qué es un principio? 2.3. ¿Qué es la transparencia? 2.4. ¿Qué es el orden público? 2.5. ¿Qué es el habeas data? 3. Marco Constitucional. 4. Marco Constitucional Electoral y Federal. 5. Conclusiones y propuestas. Bibliografía.

\section{Introducción}

Existen diversos valores y principios dentro de nuestra Constitución o Norma Rectora que coexisten, se interrelacionan y si se analizan por separado, pudiesen parecer contradictorios, sin coherencia o que no guardan armonía; por ello, es menester, estudiar la axiología y la teleología de la norma.

Así tenemos que el derecho constitucional electoral, que es una transdisciplina en evolución y perfección constante, dinámica y cuya dialéctica no para, se encuentran principios que se deben observar, dado que es obligatorio para todas las autoridades el preservar el orden e interés público; pero, lo que debemos proteger, por ser un valor esencial de toda organización política, son los sagrados, inalienables, imprescriptibles e indivisibles derechos de las personas y de ahí, los derechos políticos y electorales, valores fundamentales para la República, representativa, democrática, laica y federal.

Es por ello, que los valores fundamentales de la democracia, como lo son la libertad política, la igualdad, la probidad y la justicia, deben de perseguirse en armonía a los principios que se establecen en los artículos que van del primero 
de la Constitución hasta el treinta y ocho, pero la teleología de toda Norma Rectora o Ley Fundamental, es la protección de los derechos de las personas y dentro de ellos, el habeas data o la protección de los datos personales en el contexto de máxima publicidad y transparencia en los procesos electorales, es por ello, que los límites, entre otros casos, no están claros y debemos seguir pensando y trabajando para dilucidar los respectivos espacios en aras de la protección de los valores y principios de manera armónica, ese es el propósito del presente trabajo

\section{Conceptos básicos y problemática}

2.1. ¿Qué es un valor? Un valor es un objeto cultural creado por una agrupación humana, a través del cual, trata de preservar algo que se considera trascendente, relevante, importante y sus receptáculos pueden ser las normas, costumbres, tradiciones, usos, prácticas o diversas formas en que los pretenden preservar y proyectar hacia las nuevas generaciones. Así, el valor filosófico máximo al que aspira toda norma es a la justicia, que también se puede concretar en el aspecto de cumplir su mandato o que se preserven los valores, principios e intereses que ella encierra, para lo cual, se requieren de los principios.

2.2. ¿Qué es un principio? Un principio es un objeto cultural a través del cual o de los cuales, se puede materializar o concretar un valor, así, cuando señalamos que una persona es justa o que un juez es justo, es porque dicha persona es ética, honorable, objetiva, profesional y especializada, entonces, los principios, son acciones específicas que nos conducen a la consecución de los grandes valores, son los espacios, peldaños, pasos para lograr los grandes fines o la protección de lo trascendente, de la justicia, la verdad, la probidad, para lo cual, se requiere el orden, la seguridad, la transparencia, la honradez, la eficiencia, la eficacia, la economía y todos los principios que dentro de nuestra Constitución o Norma Rectora, se señalan para que los servidores públicos los cumplan, los ejecuten, con los fines de aplicar la justicia en aras de la paz, la seguridad, el orden e interés público para lograr el bienestar general. 
2.3. ¿Qué es la transparencia? Es el calificativo de claro, evidente, que se comprende sin duda o ambigüedades, fácil de adivinar o vislumbrar, sinónimo de translúcido. En el caso de la administración pública, la transparencia es un principio que debe cumplir todo servidor público o titular de una dependencia y quienes trabajan en cualquier nivel de gobierno, cada persona debe declarar sus ingresos e informar sus actividades en el cargo que está desempeñando, dado que el pueblo paga sus servicios, se le debe decir qué actividades realizó en el ejercicio de sus funciones, cuánto ganó y en qué tiempo, de la manera más sencilla y simple, esa es una obligación del servidor público, el cual debe tener derecho a recibir un sueldo, la seguridad en el empleo y las prestaciones respectivas.

Así en todo ejercicio republicano, cualquier persona puede ser electa, puede votar, toda persona tiene derecho a ser servidor o ser empleado público; por ello, el pueblo, la gente, debe saber quién es esa persona, su modus vivendi o forma de vida, su trayectoria, a lo que se ha dedicado, su patrimonio, que debe tener un origen legal y legítimo y a dar cuenta de sus actos, acciones o lo que realizó en el cargo que desempeñó, que debe hacerlo con honestidad, ética, eficiencia, eficacia, economía, objetividad, profesionalismo, especialización, imparcialidad, gratuidad, autonomía, independencia y transparencia, de manera principal, dado que el pueblo manda, al pueblo se le debe servir y se le debe informar, todo ello, dentro de los marcos constitucionales y los legales, en virtud a que existe el habeas data o la protección de los datos personales.

La transparencia se encuentra interrelacionada con los derechos de los humanos, con los derechos de las personas o los derechos fundamentales o constitucionales, que son las luchas de los ciudadanos para que los gobernantes o autoridades se conduzcan dentro de un marco legal o del Estado de Derecho (staatsrrecht); así, las autoridades deben hacer lo que la ley señala, establece o les obliga, como principio de legalidad y las personas o ciudadanos, pueden actuar de manera libre, de hacer todo lo que se considere prudente, siempre y cuando no violen, transgredan o incumplan la norma.

Y dentro de estos rangos o vaivenes, tenemos el derecho a la información

\section{8}


y a la transparencia y el habeas data, lo público y lo privado, la dicotomía y sus diversos espectros; hasta dónde o en qué niveles, un servidor público debe enterar a la ciudadanía o al pueblo sus aspectos personales, el servidor público está obligado a declarar y a transparentar cuánto ganó, pero no en qué lo gastó, salvo que haya sido en cuestiones ilícitas.

En el devenir histórico, tenemos, que en La Déclaration des Droits de l'homme et du Citoyen = Declaración de los Derechos del Hombre y del Ciudadano del 26 de agosto de 1789, se estableció que los representantes del pueblo francés, constituidos en la Asamblea Nacional, consideraban que la ignorancia, el olvido y el menosprecio al respeto de los derechos del hombre, eran las causas de los males públicos y de la corrupción de los gobernantes, emitían esta declaración (Les représentants du peuple francais constitués en Assemblée nationale, considérant que lígnorance, lóubli ou le mépris des droits de l'homme sont les seules causes des malheurs publics et de la corruption des gouvernements).

Así en sus artículos 12 y 13, señalan la necesidad de la fuerza pública para que se respeten y cumplan los derechos de los hombres, pero que dicha fuerza, requiere de una contribución común indispensable, legal y distribuida entre todos los ciudadanos, así, se estableció que: Tous les citoyens ont le droit de constater, par euxmemes ou par leurs représentants, la nsu écessité de la contribution publique, de la consentir librement, d'en déterminer la quotité, l'assiette, le recouvrement et la dureé = Todos los ciudadanos, en el derecho de constatar en todos sus representantes, la necesidad de contribuir de manera pública y de consentir, de manera libre, su empleo, la cuota y su duración (artículo 14).

En el mismo sentido, se estableció que: La societé a le droit de demander compte á tout agent public de son administration = La sociedad, tiene el derecho de demandar o pedir cuentas a todo agente de la administración (artículo 15).

Y en el artículo 16 de dicha declaración, se señaló: Toute société dan laquelle la garantie des droits n'est pas assurée, ni la séparation des pouvoirs 
déterminée, $n^{\prime}$ a point de constitution = Toda sociedad en la que los derechos del hombre no está asegurada, ni la separación de los poderes determinada, carece de Constitución.

Así las aportaciones francesas, son en el sentido de que toda sociedad, requiere para asegurar los derechos del hombre, una fuerza, un orden público, el cual requiere de que quienes integran dicha sociedad, financien dichas estructuras públicas, de manera legal y que una vez que los ciudadanos contribuyen al gasto público, tienen derecho de pedir cuentas a sus gobernantes o administradores, todo ello, dentro del marco constitucional o de una Norma Rectora, en la que se deben garantizar los derechos de las personas y la división de poderes, así, nace el Estado de Derecho, a través de una Constitución o el acta de nacimiento del Estado Moderno o de Derecho, en el cual, todo procedimiento debe ser constitucional y conforme a la norma.

Dichos preceptos, se establecieron en la Constitución Política de Jalisco de 1824, en la que se señalaba que dentro de la instrucción pública, se debían enseñar los derechos del hombre (artículo 260); asimismo, en la Constitución Política de la República Mexicana, del 5 de febrero de 1857, se dispuso que los derechos del hombre son la base y el objeto de las instituciones sociales (artículo primero), con una franca inclinación hacia el derecho natural.

2.4. ¿Qué es el orden público? Señalaba Hobbes, que el hombre es el lobo del hombre, que el hombre es malo por naturaleza (homo homini lupus); que su estado natural es de guerra y por tanto, si los hombres requieren los mismos satisfactores, dado que cuentan con las mismas necesidades, entonces, tendrán conflictos en aras de los mismos satisfactores, entonces, se aniquilarán y el hecho de que se encuentren, de manera permanente en guerra, implica su propia destrucción; entonces, es menester pactar para la paz y la defensa común, esto es, para establecer el orden público, lo que requiere de una fuerza superior, que obligue a la raza a respetar los derechos de los demás, para lo cual, cada uno deben ceder parte de su soberanía personal en la formación del Estado, o el ente superior y más poderosos a todos que imponga la paz, la seguridad, el orden público. 
Así, el orden público es contrario a la anarquía, los gobernantes deben hacer lo que corresponda conforme a derecho y las personas, podrán hacer lo que estimen conveniente, que no esté prohibido por la ley; por tanto, deben respetar los derechos de tercero, no cometer un delito, no atacar a la moral, la paz, el interés y el orden público, lo cual significa vivir en paz, como lo señalaron los jurisconsultos romanos: alterum non leadere, suum cuique tribuere et honeste vivere $=$ no dañar a nadie, dar a cada quien lo suyo y vivir honestamente

Entonces, el orden público es un atributo superior, es uno de los fines más importantes que tiene el Estado de Derecho, el respeto, el vivir en armonía, para que se puedan realizar todas las actividades en dicha comunidad, sociedad o agrupación humana con paz, con seguridad, con orden; así, el orden público es menester para lograr la felicidad de la colectividad y que se desarrollen los altos fines de las interrelaciones o convivencia humana.

2.5. ¿Qué es el habeas data? Son los documentos, pruebas, papeles, fojas, expedientes, actas o datos que se interrelacionan o que forman parte de la historiografía, biografía, historial, curriculum, hoja de vida o datos que son de una persona.

Entonces, el habeas data es la protección de los datos personales de un ser humano, lo complejo del asunto es que muchos datos de las personas se encuentran en manos de autoridades del sector público, del sector privado, empresas o personas que prestan servicios o del sector social o de la seguridad social, las jubilaciones o determinadas personas de esas características; entonces, dichas instancias, a priori, cuentan con información de personas, pensemos en el Registro Civil, que es una obligación de los padres registrar a un niño recién nacido y deben informar o dar a conocer datos de la familia, de uso exclusivo o reservados a dicha familia, esposos, cónyuges, hijos, abuelos o familiares; sin embargo, al entregar dichos datos a la autoridad, que los automatiza, pueden estar en cualquier momento en el ciberespacio y ser conocidos por muchas personas, por ejemplo, por traficantes de menores, entonces, la pregunta es quién debe preservar esos datos y qué sanciones existen para quienes hagan un manejo indebido de dicha información y lo 
que es peor, cualquier persona, puede obtener una acta de nacimiento en el Registro Civil en México, qué situación tan grave.

Los bancos o instituciones de crédito, cuando una persona requiere de un servicio como una cuenta o tarjeta de crédito o de manera simple, cambiar un cheque, debe darle a cualquier persona que esté en ventanilla o atendiendo dicha solicitud, datos personales, los cuales, pueden ser dados a conocer a empresas comerciales o al buró de crédito o a quien la empresa bancaria decida, gratis o tiene un costo, es correcto que se realicen estas prácticas?

De igual forma, si una persona requiere de ser atendido por una institución de seguros médicos, un hospital o darse de alta en una institución de servicios médicos, sea públicá, privada o social, requiere de proporcionar sus datos personales, que entran al ciberespacio y pueden ser manipulados por muchas personas, lo cual también es muy grave, y así, podemos seguir comentando innumerables ejemplos de cómo los datos personales de millones de seres humanos pueden ser manipulados con fines comerciales, políticos, delictivos o de diferentes maneras que afectan a las personas en su vida, en su persona, en su familia, en su sociedad y en todos los aspectos de su vida y como las cuestiones del ciberespacio están muy poco reguladas, entonces, existe impunidad y se abren las posibilidades de cometer muchos crímenes o atentar contra cualquier persona de manera impune.

Por lo anterior, el habeas data es una protección de los datos personales susceptibles de ser manipulados sin el consentimiento del titular; por lo que se debe identificar con quién se dejaron los datos, quién debe resguardarlos, cómo se deben proteger y qué seguridad tiene el titular o en caso de un manejo indebido, cómo será protegido o indemnizado, dado que es muy complejo el seguimiento o protección de datos en el ciberespacio o cuando existen miles de manipuladores potenciales o efectivos, porque en algunos casos, se considera que la protección de los datos personales difiere del derecho a la intimidad, lo cual agrava la situación en una cultura del amarillismo o de medrar o ser mercenario con asuntos privados.

Otra cuestión que agrava lo anterior, es el hecho de que una persona, de manera 
subjetiva, decide o puede decir el uso que se le da a los datos personales para efectos públicos, privados, comerciales, sociales, nacionales e internacionales, en virtud a que las legislaciones internacionales o supranacionales no están armonizadas. (ORNELAS y MARTÍNEZ: 2008, pp 731 y ss.).

Así en nuestro país, con las recientes modificaciones a la ley federal en la materia, tenemos que se ha considerado un retroceso por el hecho de que se ha vuelto más opaca; sin embargo, en el Poder Judicial de la Federación y el Tribunal Electoral, se han realizado notables avances en la materia, conforme a los criterios de la SCJN: que toda información es pública, con las restricciones de la ley en la materia; el proceso de instrucción es público, pudiéndose suprimir datos personales de las partes procesales; las sentencias ejecutorias son públicas y si así lo solicitan las partes, los datos personales serán suprimidos, las pruebas son confidenciales; el derecho a oponerse a la publicación de datos personales es cuando exista riesgo a la vida, seguridad o salud de las partes; las sentencias deberán conservar los nombres de las partes y la información deberá entregarse dentro de quince días hábiles, prorrogables una sola vez por otro tanto.

Sin lugar a dudas, una de las instituciones más transparentes del país, es el TEPJF, que para algunos juristas, se fue al extremo de transparentar en exceso, cuestiones que los propios magistrados han dicho que son riesgosas, como la publicación de sus sueldos íntegros, sus domicilios, familia, patrimonio y datos personales, que ante la inseguridad que vive el país, pudiesen ser riesgosos para que cualquier persona pueda manipular dicha información. (Pérez: 2008, pp.759 y ss.).

Por lo anterior, consideramos que debe tener, el titular de sus datos personales, el derecho de borrar, cambiar o manejarlos como considere conveniente, siempre y cuando sean veraces y conforme a derecho (recht auf informationelle selbstbestimmung = derecho a la autodeterminación informativa); por tanto, el derecho a la protección de datos personales, debe ser un derecho íntegro, protegido bajo la tutela constitucional y la legal, de manera efectiva y en donde se sancione a quienes dañen, de cualquier manera a la persona. (Puccinelli: 2008, pp. 785 y ss.). 


\section{Marco Constitucional}

La Constitución Política de los Estados Unidos Mexicanos (CPEUM), es un documento político soberano, es una ley electoral y es la Carta Fundamental (Grundnorm) establecida para la protección de los sagrados, inalienables, imprescriptibles e indivisibles derechos de las personas (Die Grundrechte).

Así nuestra Norma Rectora o Constitución, es un documento político electoral, que se encuentra, de manera íntima, interrelacionado; así, señala que en nuestro país, todos somos iguales, que toda persona podrá o deberá gozar o disfrutar de los derechos de los humanos y sus garantías que se protegen en la propia Norma Rectora y los tratados e instrumentos internacionales signados por México, los cuales, no deberán restringirse, salvo los casos de excepción, como los establece el artículo 29 CPEUM (artículo primero, párrafo primo CPEUM). De aquí que son disposiciones de orden público, interés general y observancia obligatoria para todos los sectores y personas.

Concatenado a lo anterior, la Norma Rectora, señala que son la Constitución, las leyes del Congreso de la Unión que emanen de ella y todos los Tratados que estén de acuerdo con la misma, celebrados y que se celebren por el Ejecutivo Federal y sean aprobados por el Senado de la República, serán la Ley Suprema en toda la Unión; que los jueces estatales, deberán arreglarse a la Norma Federal, por encima de las normas constitucionales o legales de los entes federados (artículo 133 CPEUM).

Además, que en la protección, defensa, tutela y garantía de los sagrados, inalienables, indivisibles e imprescriptibles derechos de las personas, se hará una interpretación de la propia Norma Rectora y de los tratados e instrumentos internacionales, conforme (Verfassunkonform) a la disposición que mayor beneficio otorgue a la persona en cuanto a su dignidad humana (artículo primero, párrafo segundo, con relación al artículo 14, ambos de CPEUM).

Asimismo, que las autoridades, dentro del marco de sus competencias, están obligadas a divulgar, a promover, respetar y garantizar los derechos humanos y sus garantías, bajo los principios de universalidad, interdependencia,

\section{4}


indivisibilidad y progresividad, bajo los principios de pro persona, pro femmine, pro hommine, pro cive, pro operatio et pro reo, de manera principal, mirando siempre lo que resulte más favorable para la persona humana (artículo primero, párrafo tercero). Debemos resaltar, que todo servidor público, está obligado a cumplir y hacer cumplir la CPEUM, tal como lo hace el Ejecutivo Federal, quien protesta guardar y hacer guardar la CPEUM y las leyes que de ella emanen, así como desempeñar, de manera leal y patriótica, el cargo de Presidente de la República, conferido por el pueblo, mirando en todo, por el bien y la prosperidad de la Unión y si así no lo hiciere, que la Nación lo demande (artículo 87 CPEUM).

En el mismo sentido, la propia Norma Rectora, señala que la educación en México, deberá desarrollar, de manera integral y armónica, las facultades del ser humano; asimismo, fomentará en el educando, el amor a la Patria, a la solidaridad, al respeto de los derechos de las personas, a la independencia y a la justicia.

De igual forma, se establece que toda persona tiene derecho a la libertad de sus ideas y a su expresión, así como a tener las convicciones y religión que estime conveniente; es derecho de las personas, el de participar, en forma individual o colectiva, en público o en privado, en ceremonias, devociones o actos de culto respectivo, siempre y cuando no sean delito o falta penados por la ley (artículos 6, 7 y 24 CPEUM).

El artículo sexto, expresa que los límites a la libertad de las ideas son: ataques a la moral, la vida privada, los derechos de terceros, provoque delito (habeas data) o perturbe el orden público, se cuenta con el derecho de réplica.

En el mismo sentido, se establece el derecho de toda persona a recibir información plural y oportuna por cualquier medio de expresión; el Estado garantizará el acceso a las tecnologías de información y comunicación, servicios de radiodifusión y telecomunicaciones, que incluyen la banda ancha $\mathrm{y}$ el internet.

La información de los entes públicos, deberá ser dada a conocer, los datos privados deberán ser protegidos conforme a derecho y las personas tendrán 
derecho gratuito a la información pública y a la obtención o rectificación de sus datos personales ante organismos autónomos, especializados e imparciales, mismos que deberán conservar dichos documentos, actualizarlos y publicarlos por vías electrónicas y la inobservancia de estas disposiciones, será sancionada por la ley respectiva.

Para observar estos principios constitucionales, se creará un organismo de transparencia y acceso a la información pública y protección de datos personales de los servidores públicos o sujetos obligados, quienes deberán observar los principios de certeza, legalidad, independencia, imparcialidad, eficacia (eficiencia, capacidad, probidad, honradez y respeto), objetividad, profesionalismo, transparencia y máxima publicidad; en cuanto al habeas data, el principio a observar, será la confidencialidad. El organismo garante emitirá resoluciones obligatorias o vinculantes, definitivas e inatacables para los sujetos obligados (artículo 6 CPEUM).

Los preceptos constitucionales, señalan que nadie deberá ser privado de su libertad, propiedades, posesiones o derechos; asimismo, que nadie deberá ser molestado en su persona, familia, domicilio, papeles o posesiones, salvo por mandato judicial que funde y motive su resolución con leyes previas al acto (artículos 14 y 16 CPEUM).

Asimismo, toda persona tiene derecho a la protección de sus datos personales, al acceso, rectificación y cancelación, a manifestar su oposición a los principios que rijan el tratamiento de datos, sea por seguridad nacional, orden público, seguridad y salud públicas o para la protección de los derechos de terceros (habeas data, artículos 6 y 16 CPEUM).

Como ya se apuntó, toda nuestra Norma Rectora o Constitución es un documento que su finalidad máxima es la preservación de los sagrados derechos de las personas, cuyo ejercicio, garantía y tutela, son la piedra angular del ejercicio de los derechos políticos y electorales de los ciudadanos, como la interrelación entre nacionalidad y plenitud en cuanto al ejercicio de los derechos políticos y electorales de la ciudadanía, en ese sentido, el habeas data es un derecho constitucional en el que confluyen derechos 
humanos de las personas y derechos políticos y electorales, así, los datos de los seres humanos deben ser privados, en otras ocasiones, se han considerado que deben ser públicos y entre la publicidad y la privacidad de los datos personales de los nacionales y los ciudadanos, todavía existen muchos aspectos que discutir, hasta donde un ciudadano, un candidato, un gobernante o una persona que ostente un cargo público, debe dar a conocer sus datos personales, la respuesta no es sencilla, por ello, es menester profundizar sobre el habeas data, qué es, sus antecedentes, alcances, límites, efectos y demás aspectos que se interrelacionan con el derecho humano a la protección de los datos personales y con los derechos políticos y electorales de los ciudadanos (Davara: 2008, pp.705 y ss.).

\section{Marco Constitucional Electoral y Federal}

Como se habrá podido apreciar, la transparencia, debe ser incluida como un principio rector constitucional electoral, que señala al Instituto Nacional Electoral (INE), como un órgano autónomo, independiente, con certeza, legalidad, independencia, imparcialidad, objetividad y máxima publicidad, que habrá que analizar a la luz del habeas data, y el orden público.

En primer lugar, tenemos las disposiciones constitucionales que se interrelacionan con el derecho constitucional electoral nacional e internacional y el habeas data, así como con el orden público:

- Artículos 1, 29 y 133 CPEUM

- Artículos 3, 6, 7, 24 y 130 CPEUM

- Artículos 6, 14, 16, 17, 18, 41, 60, 73 - XXIX S, 99 y del 103 al 107 CPEUM

- Artículos que van del 30 al 38 y 55, 58, 82 y 95, con el 5 y 123, de manera principal CPEUM 
Como se podrá apreciar, la primera problemática es en torno al registro de los candidatos a un cargo de elección popular, cuyos requisitos los tenemos en el artículo 55 CPEUM, en donde, de manera lamentable, tanto en el orden de la Norma Rectora como en la legislación, existe una confusión o mezcla entre requisitos para un cargo de elección popular y los impedimentos, lo que consideramos es que sería muy útil su separación en virtud de que para una impugnación de una candidatura, a través del Juicio para la protección de los derechos políticos y electorales del ciudadano (Juicio Ciudadano), que es en varios momentos, al separarse los requisitos de los impedimentos, se perfeccionaría el principio de que es definitivo, que en este caso, no es tan eficiente, sobre todo, cuando se presentan candidatos a ser votados por el pueblo y que después deban ser anuladas las elecciones o los votos de los ciudadanos, lo cual es muy grave para la democracia, sobre todo, costoso y peligroso.

Así como es de todos sabido, el artículo 55 CPEUM, nos señala qué características debe reunir un candidato para ser diputado federal:

a) Requisitos:

I. Ser ciudadano mexicano, por nacimiento.

II. Originario del Estado en el que se realice la elección o vecino de dicho ente federado, con residencia efectiva de más de seis meses previos a la fecha de la elección. En el caso de elección de diputación plurinominal, deberá ser originario o vecino de cualquier ente federado de la circunscripción. La vecindad no se pierde por desempeñar un cargo público o de elección popular.

III. Contar con 21 años cumplidos el día de la elección.

b) Impedimentos:

I. No estar inhabilitado en los términos del artículo 38 CPEUM.

II. No estar en servicio activo en el Ejército Federal, ni tener mando en la policía o gendarmería rural en el Distrito donde se haga la 
elección, cuando menos noventa días antes de ella.

III. No ser titular de alguno de los organismos a los que esta Constitución otorga autonomía, ni ser Secretario o Subsecretario de Estado, ni titular de alguno de los organismos descentralizados o desconcentrados de la administración pública federal, a menos que se separe de manera definitiva de su encargo noventa días previos a la elección.

IV. No ser Ministro de la Suprema Corte de Justicia de la Nación, ni Magistrado, ni Secretario del Tribunal Electoral del Poder Judicial de la Federación, ni Consejero Presidente o consejero electoral en los consejos del Instituto Nacional Electoral o, dentro del propio INE, no ser Secretario o Director Ejecutivo o formar parte del personal profesional directivo, salvo que se haya separado del cargo, en forma definitiva, tres años previos a la elección.

V. Los Gobernadores de los Estados y el Jefe de Gobierno del Distrito Federal, no deberán ser electos en los entes de sus respectivas jurisdicciones, cuando se encuentren en el cargo o se separen en forma definitiva de dicha función.

VI. Los Secretarios del Gobierno de los Estados y del Distrito Federal, los Magistrados, Jueces Federales, del Estado o del Distrito Federal, así como los Presidentes Municipales o Delegados titulares en el Distrito Federal, no deberán ser electos dentro de sus jurisdicciones, salvo que se separen, de manera definitiva del cargo, noventa días previos a la elección.

VII. No ser Ministro de culto religioso.

VIII. No estar comprendido en las incapacidades señaladas en el artículo 59 CPEUM, respecto a las reelecciones, que en el caso de los diputados federales, podrá ser hasta por tres ocasiones y en cuanto a los Senadores de la República, sólo en una ocasión. 
Como se habrá podido apreciar, la Norma Rectora o Constitución, señala que son requisitos, lo cual es diferente a impedimentos, lo cual convendría diferenciar y serviría para facilitar y clarificar a las autoridades administrativas electorales, los documentos que se requieren para el registro de los candidatos a los cargos de elección popular.

Así, por ejemplo, el requisito del artículo 55, fracción primera, de ser ciudadano mexicano por nacimiento, el documento ideal para acreditar la nacionalidad, es el acta de nacimiento, la cual, se encuentra en el Registro Civil o institución equivalente en cada ente federado; entonces, se le solicita a quien desea ser registrado como candidato a algún cargo de elección popular su respectiva acta de nacimiento, la cual se debe entregar.

Como opciones para la trascendencia del habeas data y del orden público, tenemos que dichas actas sólo deben ser conocidas por quienes deberán calificar los requisitos de idoneidad para ser candidato, de nadie más; y si por ejemplo, algún ciudadano, partido, coalición o cualquier ciudadano, mirando el interés u orden público, que se cumpla, las autoridades electorales, deberían verificar la autenticidad de dichos datos del acta de nacimiento con las autoridades del registro civil, que se supone, sus archivos, se encuentran ordenados y sistematizados en forma electrónica, pero, por ningún motivo, los datos personales del candidato, deben estar en manos de todos los integrantes de los organismos administrativos electorales, sean locales o nacionales, de los representantes de los partidos políticos, de la prensa o de cualquier otra persona, salvo que el propio candidato, los quiera entregar, de manera voluntaria, las autoridades sólo deben verificar si se cumple el requisito, dictaminar que se cumple el requisito constitucional y nada más.

Los demás datos, no se deben ventilar en público, en este caso, sólo si es nacional, si reúne la edad y si no se encuentra inhabilitado o impedido por disposición judicial, que como se aprecia, estamos ya en otra jurisdicción, lo cual se podría comprobar con las autoridades penales, por las mismas vías (electrónicas y de autoridad electoral a las autoridades de los poderes judiciales que correspondan), pero sin inmiscuirse en otros datos personales, salvo, 
como ya se expresó, si el propio candidato los quiere mencionar en público, lo cual es diferente a los famosos "filtros" a los medios que manipulan a la opinión pública y que dichos datos personales, pueden ser objeto de ataques personales, delitos, propaganda negra, difamaciones, injurias, calumnias o de muchas otras desviaciones, que son muy comunes, dada nuestra poca cultura cívica, política y de respeto; por tanto, no nos debemos apartar que el fin legal, es sólo de verificar si la persona que quiere ser candidato, cumple los requisitos para ser electo y no está impedido para ello y nada más, todo ello dentro de la idea de in dubio pro cive, se supone que todos los actos son de buena fe, salvo prueba en contrario, lo cual se podría verificar de autoridad a autoridad, dentro del respeto al habeas corpus y el orden público, que es, como se manifestó, el verificar el cumplimiento de los requisitos para poder ser candidato a un cargo de elección popular.

Como se habrá podido apreciar, estamos hablando de un sólo ejemplo en la materia político electoral, pero existen muchas más posibilidades de trabajar otras cuestiones, como lo es el domicilio, la cuestión fiscal, los recursos y el financiamiento, tanto público como el privado, las licencias o permisos de los servidores públicos y muchos temas más que bastaría una interrelación entre autoridades, dictámenes o certificaciones de validez o idoneidad de documentos para que una persona cumpla sus requisitos o se evidencie si tiene o no impedimentos para poder ser candidato a un cargo de elección popular.

Tal como lo expresó el Presidente del Tribunal Electoral del Poder Judicial de la Federación, el Magistrado Constancio Carrasco Daza, que los sectores sociales, tienen la percepción de un divorcio entre gobierno y sociedad, alimentado por la desigualdad social, la impunidad y el cuestionamiento ético al desempeño público. Por ello, señaló, que era menester cerrar la brecha entre sociedad y gobierno, a través de una mayor transparencia y mejor rendición de cuentas, lo cual compartimos e insistimos, que el TEPJF, es una institución ejemplo en materia de transparencia y que dichos mecanismos siguen siendo perfectibles (Cfr. La Jornada, 8 de septiembre de 2015, p. 16).

Por lo anterior, la gran institución, que es el TEPJF, sin lugar a dudas, de 
punta, de uso de tecnologías para una justicia expedita, que es un tribunal sin rezago, que se hace justicia expedita en la protección de los derechos políticos y electorales para la ciudadanía y demás avances, este sería otro elemento de vanguardia, que seguiría colocando a esta importantísima institución como ejemplo que es a seguirlo siendo.

\section{Conclusiones y propuestas}

Los valores y principios constitucionales de la transparencia, los podemos apreciar de la siguiente forma:

1. Los sagrados, inalienables, imprescriptibles e indivisibles derechos de las personas son la base y el objeto de la Norma Rectora, de las instituciones y del servicio al público. Así, los grandes valores de la constitucionalidad y de la legalidad, se ubican en la igualdad, en la libertad, la probidad en consecución de la justicia, como el máximo valor del derecho, que es el cumplimiento de la norma. De aquí la protesta que deben rendir los servidores públicos de cumplir y hacer cumplir la Norma Rectora y la ley a nivel local e internacional, de respetar el habeas data, de resolver conforme a la constitución y a la ley sus actos, debiendo fundar y motivarlos en aras de los fines de la sociedad, que son la conservación de la paz, el orden y el interés público, de ahí la necesidad de su observancia general.

2. Así tenemos que los principios constitucionales, en aras de conseguir los grandes valores, que son de manera principal, la transparencia, como forma de conducirse un servidor público, dentro del espectro de valores, se debe interrelacionar con los principios de honradez, respeto, objetividad, profesionalismo, especialización, con el respeto a los derechos de petición e información, indisolubles e interrelacionados; de manera imparcial, con ética certera, oportuna, completa, con eficiencia, eficacia, economía y que la trasparencia sea clara, evidente y con la máxima publicidad, todo ello en armonía a los demás valores y principios constitucionales, legales y los establecidos en los tratados e instrumentos internacionales. 
3. Por lo anterior, se propone, que todos los servidores públicos, deban ser capacitados en la protección de los grandes valores, principios e intereses de la República y del planeta.

4. Las autoridades electorales, tanto las administrativas como judiciales, locales y federales, deben interactuar, en aras de cumplir con el orden público y respetando el habeas data para verificar si los candidatos cumplen con los requisitos constitucionales y los legales.

5. Las diversas autoridades de la República, tal como se ordena en al artículo primero CPEUM, deben sistematizar sus archivos en aras del orden público y del respeto al habeas data, con niveles de eficiencia, eficacia y economía en aras de tener elecciones más transparentes, de mayor publicidad y donde se cumplan todos los principios rectores electorales de la constitucionalidad, legalidad, certeza, independencia, imparcialidad, profesionalismo, especialización y objetividad, además de los expresados como objeto principal del presente opúsculo.

-Constitución Política de los Estados Unidos mexicanos.

Bibliografía

-Constitución Política de Jalisco de 1824.

-DAVARA Rodríguez, Miguel Ángel: La protección de datos y las comunicaciones electrónicas, en la obra colectiva La Ciencia del Derecho Procesal Constitucional. Estudios en homenaje a Héctor Fix Zamudio en sus cincuenta años como investigador del derecho, coedición UNAM, IIJ, Marcial Pons, México, año 2008, en especial, el tomo VII: Procesos constitucionales de la libertad, pp. 705 y ss.

-ORNELAS Núñez, Lina y MARTÍNEZ Rojas, Edgardo: Transferencias internacionales de datos personales: su protección en el ámbito del comercio internacional y de seguridad nacional, en el obra colectiva La Ciencia del 


\section{Bibliografía}

Derecho Procesal Constitucional, op. cit., tomo VII, pp. 731 y ss, año 2008.

-PÉREZ Maldonado, Valeriano: Protección de datos personales y acceso a la información del Poder Judicial de la Federación, en la obra colectiva La ciencia del Derecho Procesal Constitucional, op. cit., tomo VII, pp. 759 y ss, año 2008.

-Periódico, La Jornada, 8 de septiembre de 2015, p. 16.

-PUCCINELLI, Óscar: Apuntes sobre el derecho, la acción y el proceso de habeas data a las décadas de su creación, en la obra colectiva La Ciencia del Derecho Procesal Constitucional, op. cit., tomo VII, pp. 785 y ss, año 2008. 